\title{
Born in the lab: Hydrocarbon fuels ditch their fossil origins
}

\author{
By Eva Karatairi \\ Feature Editor James E. Miller
}

$F^{a}$ ossil fuel stocks, the result of nature's millenia-long efforts to store solar energy, have been the energy treasure chest of humankind. Yet, every time the chest is opened to release energy, stored carbon is released as well in its primordial oxidized form. Today, $\mathrm{CO}_{2}$ is accumulating at a vertiginous pace in the atmosphere. Based on overwhelming scientific evidence (i.e., hard experimental data, including the known heat-trapping properties of $\mathrm{CO}_{2}$ ), this process has been shown to be the principal cause for rising ocean and atmospheric temperatures. Thus, a global effort to limit the temperature rise to $2^{\circ} \mathrm{C}$ or less within this century is under way.

The task is challenging from many perspectives: While it is clear we must stop releasing more $\mathrm{CO}_{2}$ into the air, liquid hydrocarbon $(\mathrm{HC})$ fuels are indispensable to modern economies. Although electrification from nonfossil fuel sources is making strides in the personal transportation market, liquid HCs, with their high energy densities, continue to fuel large trucks, airplanes, commercial ocean applications, and heavy equipment. Their substitution does not seem like a realistic option-at least for the moment. Fortunately, synthetic fuels with a nonfossil origin are increasingly becoming a viable alternative.

The target is clear and appealing: We need technologies that will imitate nature by utilizing renewable energy to recombine $\mathrm{CO}_{2}$ and $\mathrm{H}_{2} \mathrm{O}$ into an energetic $\mathrm{HC}$ form (e.g., through the intermediate creation of synthesis gas). Syngas is a mixture of $\mathrm{CO}$ and $\mathrm{H}_{2}$, which can be exothermally converted into fuels through processes such as the commercially practiced Fischer-Tropsch (FT) technology. These $\mathrm{CO}$ and $\mathrm{H}_{2}$ precursors are the products of nominally straightforward $\mathrm{CO}_{2}-$ and $\mathrm{H}_{2} \mathrm{O}$-splitting reactions.

"The path to successfully converting the solar energy into renewable fuels and initiate a significant change in the energy economy must simultaneously fulfill four requirements," said Sophia Haussener, an expert in photoelectrochemistry and solar thermochemistry from École Polytechnique Fédérale de Lausanne (EFPL). "It must be done efficiently. It must be robust and stable, scalable, and therefore cheap. And of course, sustainable," she explained.

Sustainability directly implies the use of renewable energy sources, among which solar energy is the most abundant and, therefore, the most scalable over the long term. In this context, processes that use sunlight have the greatest potential impact, and would be expected to play an increasingly important role. Furthermore, for this process to remain carbon neutral, the use

of ambient $\mathrm{CO}_{2}$ and $\mathrm{H}_{2} \mathrm{O}$ as the respective carbon monoxide and hydrogen source is necessary.

Electrochemical reduction of carbon dioxide and water is the most mature pathway for recycling the two into syngas. The method can be based on either solar cells or wind turbines to generate the electricity that is necessary to break down $\mathrm{CO}_{2}$ and $\mathrm{H}_{2} \mathrm{O}$. Conceptually, in the electrochemical approach, $\mathrm{CO}_{2}$ and $\mathrm{H}_{2} \mathrm{O}$ are both reduced at the cell cathode, while oxygen is evolved at the anode. However, another reaction, the equilibrium water-gas-shift reaction $\left(\mathrm{CO}+\mathrm{H}_{2} \mathrm{O} \leftrightarrow \mathrm{CO}_{2}+\mathrm{H}_{2}\right.$ ) also plays a role. In contrast to $\mathrm{H}_{2} \mathrm{O}$ splitting alone, other reactions and products are also possible during coprocessing.

The minimum amount of energy that must be provided is thermodynamically defined. In practice, the energy required significantly exceeds the minimum by a value called the overpotential. Catalysts can raise the efficiency (reduce the overpotential) as well as the selectivity in such systems and reduce the overall costs. A variety of homogeneous catalysts in solutions and heterogeneous catalysts at the electrode surface has been developed, based on $\mathrm{Cu}$ and other transition-metal catalysts (e.g., Ag, Au, Pt, $\mathrm{Cu}, \mathrm{Sn}$ ), metal alloys, metal oxides, metal complexes, polymers, and biomolecules.

Several companies are currently moving electrochemical synfuel technology to market. One such company, Opus 12, first introduced a low-temperature reactor and catalyst system in 2015. Their electrochemical conversion process is based on a proton-exchange membrane (PEM) that is not optimized for generating $\mathrm{H}_{2}$, as PEMs commonly are, but is modified to have high selectivity for carbon dioxide utilization. Fast forward two years, the team is now trying to scale up their device "from something you can hold in your hand to something the size of a refrigerator that can take up to 500 pounds of carbon dioxide per day and convert it into higher value products," according to Kendra Kuhl, CTO, in an earlier interview for Smithsonianmag.com. While syngas is one potential product, the company is also pursuing more direct routes to hydrocarbons. Kuhl believes that "developing a commercial process will spur further research in this area."

Ceramatec has pursued a high-temperature solid-oxide-based co-electrolysis (SOEC) method for creating syngas, which is further converted by FT HC synthesis. Materials of choice for SOEC electrodes are very often nickel ceramic-metal (cermet) composites, such as nickel-doped yttria-stabilized zirconia 
(Ni-YSZ) for the anode and nickel-doped cerium dioxide $\left(\mathrm{Ni}-\mathrm{CeO}_{2}\right.$ ) or perovskite-type lanthanum strontium manganite/ yttria-stabilized zirconia (LSM-YSZ) for the cathode.

"Our overall plan for solid-oxide co-electrolysis has always been fossil-free drop-in sustainable fuels," said Joe Hartvigsen, senior engineer for Solid Oxide Fuel Cell, Hydrogen, and Synfuels Technologies at Ceramatec. ("Drop-in" meaning that fuels can be dropped directly into the fuel distribution system and run into today's engines.) "We've had to piece together R\&D projects to show the various elements, as the US isn't as active in this area as Germany and Denmark. We're about to commission a two barrels (bbl)/day Fischer-Tropsch unit that is a small fraction of the size of the Sunfire 1 bbl (159 liters) unit."

Sunfire, located in Germany, has taken major steps toward industrialization of steam electrolysis. In contrast to the co-electrolysis approach, Sunfire's "power-to-liquid" (PTL) process is based on three components: high-temperature solid-oxide electrolysis to produce $\mathrm{H}_{2}$, reaction of $\mathrm{H}_{2}$ with $\mathrm{CO}_{2}$ to produce $\mathrm{CO}$ (reverse $\mathrm{H}_{2} \mathrm{O}$-gas shift reaction, RWGS), and fuel synthesis. Their teaming-up with the Norwegian clean tech company Nordic Blue Crude, has resulted in the first commercial plant for production of synthetic HCs from renewable energy, $\mathrm{H}_{2} \mathrm{O}$, and $\mathrm{CO}_{2}$. Gunnar Holen, CEO of Nordic Blue Crude, gives his insight: "Sunfire has made major improvements of their RWGS technology, such that Capex (capital expenditure) and Opex (operating expense) will be significantly reduced." Holen said they are also evaluating the high-temperature co-electrolysis approach, which should reduce Capex and Opex even more.

For Holen, this technology is vital for a rapid reduction in $\mathrm{CO}_{2}$ emissions, because it allows the use of existing engines and distribution systems. "In Norway only, we plan to set up 10 full scale plants (each for 100 million 1/year), which will produce about one-third of the diesel consumed in Norway today. This will reduce $25 \%$ of the total emissions from transportation in Norway. If things go as we hope and believe, we will see an important percentage of the transportation fleet utilize this technology in the next 5-10 years," he said.

Hartvigsen is more circumspect and thinks we need a decade or more of intense activity to reach a production rate with any significant impact. "We're ready to start, renewable power can now be produced at a cost that is low enough to make fuels." But, he added, the effort must be supported by regulatory situations that give value to reducing $\mathrm{CO}_{2}$ and have committed project developers with the financial ability to make this prospect a reality. In the meantime, Ceramatec's solid-oxide electrolysis stacks have been chosen as part of the Mars Oxygen In Situ Resource Utilization (ISRU) Experiment (MOXIE), one of the seven instruments on the
Mars rover that is set to land on the red planet in 2021. MOXIE will have to prove that electrochemical oxygen production from the $\mathrm{CO}_{2}$-rich Martian atmosphere is possible for future manned missions. Opus 12 is also working with NASA, to find ways of using $\mathrm{CO}_{2}$ and $\mathrm{H}_{2} \mathrm{O}$ splitting to create a habitable environment on Mars. But, as Kuhl said, "we have a way to go, ensuring that Earth remains habitable first."

While these companies push forward in the market place, academia is providing important advances and insights that will continue to improve process energy efficiencies and reduce costs. Commenting on the low-temperature electrolytic process, Amin Salehi-Khojin, director of the Nanomaterials and Energy System Laboratory, at the University of Illinois at Chicago, pointed out, "During $\mathrm{CO}_{2}$ reduction, $\mathrm{CO}_{2}$ converts to a $\mathrm{CO}_{2}$ intermediate, which then turns to $\mathrm{CO}$ and $\mathrm{H}_{2}$ (syngas). The first stage is very energy consuming. It has a big barrier for decomposition because it is a single-electron transfer process. That is the source of the inefficiency in the $\mathrm{CO}_{2}$ conversion."

In 2012, Salehi-Khojin's team showed that they can convert $\mathrm{CO}_{2}$ and $\mathrm{H}_{2} \mathrm{O}$ to syngas, with overpotential values as low as $54 \mathrm{mV}$. They did so by using an ionic liquid electrolyte and a silver catalyst that function synergistically; a low energy $\mathrm{CO}_{2}$ complex forms in the ionic liquid, which in turn leads to a lower energy intermediate on the catalyst. But making this process practical at a large scale was still a big challenge. Salehi-Khojin's team came up with the idea of using inexpensive transition-metal dichalcogenides (e.g., bulk molybdenum disulfide) as catalysts; these materials showed 1000 times better performance and were 100 times cheaper than silver. Now they are about to publish their results on a new electrolyte that will replace the expensive ionic liquid and has an equal or even better performance. "Everything is ready for the scale-up and can be done with the energy of the sun or other renewable energy," he said.

To take advantage of solar energy, Salehi-Khojin and his coworkers are relying upon another widely pursued, but commercially less mature, approach: photoelectrochemistry (PEC). PEC directly couples the capture and conversion of solar photons via semiconductors to electrodes capable of promoting desired electrochemical reactions, whereas the electrolytic process is somewhat independent of and agnostic to the source of electricity. PEC, together with solar thermochemical $\mathrm{H}_{2} \mathrm{O}$ and $\mathrm{CO}_{2}$ splitting, which seeks to improve upon the other two approaches by entirely circumventing the intermediate conversion of photons to electricity, will be discussed in the December issue of EQ to fill in areas of the map that help scientists find their way toward a nonfossil fuel future. 